TITLE PAGE

\title{
Conceptualising and measuring spatial indicators of employment through a liveability lens
}

Hannah Badland, Melanie Davern, Karen Villanueva, Suzanne Mavoa, Allison Milner, Rebecca Roberts, Billie Giles-Corti

\section{Corresponding author}

Dr Hannah Badland

McCaughey VicHealth Centre for Community Wellbeing

Melbourne School of Population and Global Health

The University of Melbourne

Level 5, 207 Bouverie Street

Parkville

Victoria 3010

Australia

Email: hannah.badland@unimelb.edu.au

Telephone: +61383440943

\section{Authors' affiliation}

McCaughey VicHealth Centre for Community Wellbeing, Melbourne School of Population and Global Health, The University of Melbourne, Melbourne, Australia

\section{Conflict of interest statement}

All authors declare they have no conflict of interest.

Manuscript word count (including references): 4,749

Abstract word count: 255

Number of references: 46

Number of figures: 2

Number of tables: 1

\section{Acknowledgements}

This work was supported by the NHMRC Centre for Excellence in Healthy Liveable Communities (\#1061404) and The Australian Prevention Partnership Centre (TAPPC) (the latter is supported by NHMRC, ACT Health, NSW Health, the Australian National Preventive Health Agency (ANPHA), the Hospitals Contribution Fund of Australia (HCF) and the HCF Research Foundation). BGC is supported by an NHMRC Principal Research Fellow Award (\#1004900). All authors are in part, supported by VicHealth. 


\section{ABSTRACT}

Employment is a well-known social determinant of health and wellbeing and important for the liveability of a region. Yet, spatial data are rarely used to understand barriers and facilitators of accessing employment within a city. Therefore it remains challenging to plan cities that provide equitable opportunities for urban job seekers. This paper sought to: 1) identify urban planning and neighbourhood spatial attributes that facilitate access to employment; 2) conceptualise how neighbourhood attributes that facilitate accessible urban employment may be related to health and wellbeing behaviours and outcomes; and 3) isolate potentially important neighbourhood-level spatial measures that policy-makers and planners could use to assess urban employment accessibility. A conceptual framework was developed through a social determinants of health lens, where more upstream (e.g., neighbourhood attributes) and more downstream (e.g., behaviours, intermediate outcomes) determinants of urban employment were identified in relation to long-term health and social outcomes of interest. Six potential neighbourhood spatial measures of employment were identified. These were classified into measures of: access to employment $(n=4)$, local employment $(n=1)$, and neighbourhood employment level $(n=1)$. The spatial measures proposed rely on routinely collected administrative datasets existing within Australia (i.e., census data); therefore can be replicated over time and data are available nationally. Together, this research identified a suite of potential (and readily available) spatial measures that can be used to assess selected neighbourhood attributes as they relate to urban employment access. Such spatial measures can be used to inform future planning decisions that integrate policies across multiple sectors, thereby improving employment accessibility in an urban context.

Keywords: geographical information systems; liveability; policy; social determinants of health; urban planning

TITLE: CONCEPTUALISING AND MEASURING SPATIAL INDICATORS OF EMPLOYMENT THROUGH A LIVEABILITY LENS

\section{MAIN BODY}

\subsection{INTRODUCTION}

\subsection{Employment as a social determinant of health}

Employment is a well-known social determinant of health and wellbeing (Theorell 2000). Employment that offers a decent living-wage, opportunities for professional development, a degree of flexibility, and work-life balance improves prospects for financial security, personal development, and social 
networks (Strategic Review of Health Inequalities in England post-2010 2010), and hence protects health (Wilkinson and Marmot 2003), as well as providing a sense of autonomy and control (Theorell 2000). Conversely, being unemployed or working in lower-skilled occupations can negatively impact both physical and mental health (Theorell 2000). For example, declines in physical functioning occur approximately 12 years earlier for those in lower-skilled jobs (versus higher-skilled), and a positive relationship exists between a person's employment grade and sense of control (Chandola et al. 2007). Moreover, employment patterns tend to mirror the social gradient, whereby unemployment and temporary employment rates are highest in those with the least skills and qualifications, people with disabilities and mental illnesses, some ethnic minorities, carers and single parents, and older and younger workers; thus contributing to a cycle of entrapment (Strategic Review of Health Inequalities in England post-2010 2010).

\subsection{Employment accessibility}

Most of the employment and health literature has focused on the associations between different types of employment (including unemployment and underemployment) across a range of health and social outcomes (Roelfs et al. 2011; Strategic Review of Health Inequalities in England post-2010 2010; Milner et al. 2014). While important, such evidence does not consider the more upstream neighbourhood-level determinants that contribute to the location and accessibility of urban employment opportunities. The available evidence suggests that the location of employment may be important for health and wellbeing. For example, time spent commuting to work has been negatively associated with: walking (Brownson et al. 2005); community cohesion (Jackson 2003); time spent with family or volunteering (J. Wilson 2000); obesity risk (Frank et al. 2004); and stress levels (Van Rooy 2006). For those living in an urban context and seeking employment in a single occupation with a fixed location, having more transport opportunities available within a neighbourhood increases the range of job opportunities that can be accessed locally by walking or cycling, or readily by public transport. In turn, this can shorten the job search period (Korsu and Wenglenski 2010) and time spent commuting (Zhao et al. 2011). Of the few studies that have examined physical access to employment under these conditions (i.e., urban setting, static location), the availability of automobiles (Dobbs 2005) and public transport (Sanchez 1999) is critical for accessing a distributed labour market, and therefore labour force participation, particularly in regions with a centralised labour force (Kjellstrom and Hinde 2006).

Automobiles remain by far the dominant commute mode choice in most developed countries (US Department of Transportation and Bureau of Transportation Statistics 2003; Department for Transport 2013); yet for some, car-reliant journeys often involve long commute times, increasing the risk of traffic injury (Weir et al. 2009) and contributing to congested roadways. Longer commute journeys have also been associated with higher levels of employee anxiety (Van Rooy 2006). In an effort to reduce vehicle miles travelled (of which employment is a significant contributor), researchers have compared job-housing and retail-housing balance (Cervero and 
Duncan 2006); concluding that having access to a job within a four mile radius was a more effective strategy for reducing overall vehicle distances travelled, compared with a higher level of local retail access.

\subsection{Area-level employment}

Another important upstream determinant of health and wellbeing is neighbourhood unemployment levels (known in Australia as local employment). Higher levels of local unemployment have been linked to increases in localised mortality rates in a range of countries (van Lenthe et al. 2005). After controlling for household income, those who live in neighbourhoods of concentrated disadvantage are more isolated and have fewer external social networks (i.e., bridging social capital) (Warr et al. 2009), especially when compared with those employed or well-educated (van Lenthe et al. 2005; Baum et al. 2009). Further, job-seekers often rely on neighbours for potential employment contacts (Galster 2010). Therefore living in neighbourhoods of high unemployment may increase an individual's duration of unemployment and underemployment (Korsu and Wenglenski 2010), further compounding the effects of local unemployment. Indeed, a French study identified those living in disadvantaged areas with poor job accessibility had an increased risk of long-term unemployment, with the most vulnerable being single parents with at least one young child (Korsu and Wenglenski 2010). Other recent research suggests a positive relationship between area-level local unemployment and individual-level job insecurity perceptions (Milner et al. 2013).

\subsection{Matching individual skills to area-level employment opportunities}

The match between localised employment opportunities and local skillsets is also worthy of attention. Internationally the trend suggests that higher-skilled workers tend to live closer to the inner city, and those with lower-skill levels live further out (Stoll 2005). This patterning may largely occur because of housing affordability, whereby urban fringe developments are said to provide more 'affordable' housing (Currie and Delbosc 2011). This trend potentially also reflects job opportunities, where higher-skilled jobs tend to be located in vibrant inner city areas (Florida 2011) (thus providing more direct and better serviced public transport commutes for those who are likely to fill these roles), whereas the lower-skilled jobs are often more dispersed through suburbs and urban fringe areas. Depending on the available transport infrastructure within these areas, there may be considerable commuting costs attached (Department of State Development 2013). Hence, those working in lowskilled employment located more peripherally may need to engage in longer commutes to access jobs; rely on private automobiles for the workplace commute, as existing public and active transport infrastructure may be insufficient; or relocate to areas with greater employment opportunities. These are costly alternatives for individuals that can widen inequities and remain unviable options for many disadvantaged people seeking employment.

\subsection{Setting the context}


Although this work has been conceptualised from an international perspective, it uses Australian data (Victoria) to build a case for demonstrating how a suite of urban employment measures could be developed and applied in future. Indeed, this papers forms part of a wider Victorian project seeking to measure 'liveability'. Liveability is a concept used in Australian urban planning policy (State Government Victoria 2014; New South Wales Planning and Infrastructure 2014; Western Australian Planning Commission and Department for Planning and Infrastructure 2009), and is highly consistent with the social determinants of health. Informed by our recent literature reviews investigating measures of diverse domains of urban liveability (H Badland et al. 2014b; Lowe et al. 2013), we defined liveability as being 'safe, attractive, socially cohesive and inclusive, and environmentally sustainable; with affordable and diverse housing linked to employment, education, public open space, local shops, health and community services, and leisure and cultural opportunities; via convenient public transport, walking, and cycling infrastructure'.

An important note to the reader is that this research focuses on employment within the urban context and for occupations that are typically based at static locations. Thus this paper generalises to the most common types of occupations within the Australian population; these are likely to be higher-skilled workers employed (or seeking employment) in urban areas (Australian Bureau of Statistics 2012). Higher-skilled workers are defined as those with having at least an upper secondary school qualification (Chaloff 2008), and in Australia this accounts for $85 \%$ of 25-34 year olds through to $58 \%$ of $55-64$ year olds (Roberts 2012). Approximately $80 \%$ of jobs in Australia require post-school qualifications (K. Wilson et al. 2011), and $85 \%$ of Australia's jobs are located in urban settings (Australian Bureau of Statistics 2011a). Therefore, this paper is less generalizable to occupations that may be located outside of urban areas (e.g., manufacturing hubs located in periurban settings), or for those who travel to numerous locations as part of their occupation (e.g., tradespeople).

\subsection{Aims of the research}

Spatial data are rarely used to understand barriers and facilitators of accessing employment, so from a policy perspective it remains challenging to plan cities that provide equitable opportunities for urban job seekers. This paper fills this void by: 1) identifying urban planning and neighbourhood spatial attributes that facilitate access to employment; 2) conceptualising how neighbourhood attributes that facilitate accessible urban employment may be related to health and wellbeing behaviours and outcomes; and 3) isolating potentially important neighbourhood-level spatial measures that policy-makers and planners could use to assess urban employment accessibility. Three different methods were used to address the aims of this paper: 1) a review of planning and policy documents to identify urban employment accessibility guidelines or requirements; 2) a review of scientific literature to identify urban employment measures used elsewhere; and 3) an academic assessment of the 'usefulness' of the identified measures from a spatial perspective. 


\subsection{METHOD}

\subsection{Conceptual framework development}

For each liveability domain we developed a conceptual framework hypothesising the relationship between neighbourhood attributes and health and wellbeing. The conceptual frameworks were developed through a social determinants of health lens. For this study, more upstream (e.g., neighbourhood attributes) and more downstream (e.g., behaviours, intermediate outcomes) determinants of urban employment were identified in relation to long-term outcomes of interest (Figure 1). The well-established academic evidence base guided these associations (Theorell 2000; van Lenthe et al. 2005; Strategic Review of Health Inequalities in England post-2010 2010). The conceptual framework was then used to identify suitable upstream neighbourhood-level spatial measures associated with selected urban employment-related behavioural, intermediate, and long-term outcomes.

\subsection{Rationale for selection of measures and scales}

There were two overarching considerations for selecting the neighbourhood-level measures of urban employment. First, the measures identified needed to be spatially attributable (i.e., the unit of measurement had to be within a spatially defined boundary). Spatially defined boundaries facilitate contrast and comparison of diverse neighbourhoods or regions to understand what types of infrastructure are available within a defined areal unit. Second, the measures had to be conceptualised at a fine-grained scale. Finer-grained data (i.e., smaller areal unit data) are generally regarded as more appropriate for studying neighbourhood effects in an urban context. Not only can they be aggregated to larger regional administrative units if required (Kwan 2012), but also provide the flexibility for identifying localised pockets of employment-related disadvantage. Indeed, it has been shown that in many instances the local neighbourhood context appears a better predictor of an individual's behaviour, rather than regional- or city-level attributes (Learnihan et al. 2011). Indeed, the SA3 level (an area conceptualised as a suburb with between 30,000 and 130,000 residents) was considered to be an appropriate size for which local employment opportunities could be anticipated in an urban setting, and also reflects a commute distance readily accessible by active travel or public transport (HM Badland et al. 2007).

\subsection{Selecting the spatial measures}

The lead author conducted a literature search of Victorian (state) and selected Australian (national) urban policy and planning documents related to potential spatial attributes of employment. Spatial measures of employment used previously in adult public health and urban design research were also reviewed. All measures identified were included at this stage. The co-authors then reviewed these measures in relation to the following criteria:

1) Does the spatial measure fit within the proposed conceptual framework? 
2) Are spatial data readily available to create a measure that can be replicated over time in an urban context?

3) Does the proposed measure align with state or national urban planning policies?

Each identified urban planning and research measure was reviewed against these criteria. A list of relevant spatial datasets was compiled for the measures that fulfilled these criteria. When measures were identified as being important based on the conceptual framework but were not located through the literature review, the authors created fit-for-purpose measures based on the current academic evidence.

\subsection{RESULTS}

In this proposed conceptual framework the upstream determinants of access to urban employment (towards the left side of Figure 1) focus on neighbourhood-level measures; existing urban policies and planning measures informed these. Based on the evidence, the three main neighbourhood attributes that influence urban employment are: access to employment, including the distance to, and density and types of different jobs; local employment; and neighbourhood employment level. As the framework moves downstream to the right, the measures become more behavioural, impacting intermediary outcomes, and conclude with long-term implications, including health and wellbeing outcomes.

To provide an operational example using our proposed conceptual framework, those whose skills match the local urban employment opportunities (a neighbourhood attribute) tend to have greater employment opportunities available to them. Therefore, they are more likely to gain employment, which provides financial security and reduces time spent commuting, which in turn provides positive mental and physical health benefits and positively impacts sense of control (longterm outcomes). Accordingly, this conceptual framework could be used to inform planners and decision-makers of how their urban planning decisions impact the health and wellbeing of residents.

\section{Insert Figure 1 about here}

Applying our pre-determined rationale and criteria to the conceptual framework resulted in six potential neighbourhood spatial measures of employment that were relevant to the Victorian urban region. These were classified into measures of: access to employment $(n=4)$, local employment $(n=$ 1), and neighbourhood employment level $(n=1)$ (Table 1). Commute mode measures for accessing employment were the most well developed spatial measures. We found no urban planning policies in relation to informing appropriate work-home commute distances.

Insert Table 1 about here 
For access to employment and neighbourhood employment level we propose generating each of these measures using geo-coded data derived from a residential address or operationalized at a small administrative areal unit. In Australia this equates to a Statistical Area (SA) 1 unit, approximating to an area with 400 people domiciled (Australian Bureau of Statistics 2011b). We intend to operationalise local employment at the SA3 level (commonly conceptualised as a 'suburb', with $30,000-130,000$ residents) (Australian Bureau of Statistics 2011b). By way of example, Figure 2 maps the prevalence of those who live and work within the same SA3 across metropolitan Melbourne. Of note, all of the spatial measures presented in Table 1 rely on routinely collected administrative datasets in Australia (i.e., census data); therefore they can be replicated over time and applied to urban settings across Australia.

\section{Insert Figure 2 about here}

\subsection{DISCUSSION}

This paper builds on the body of literature showing access to meaningful employment is an important social determinant of health and contributes to reducing health inequalities (Strategic Review of Health Inequalities in England post-2010 2010; Roelfs et al. 2011; van Lenthe et al. 2005). Our work moves beyond exploring associations by hypothesising a conceptual framework for how upstream neighbourhood-level urban employment opportunities might influence the more downstream behavioural, intermediate, and long-term health and wellbeing outcomes. As well, it identified a suite of potential (and readily available) spatial measures that can be used to assess selected neighbourhood attributes as they relate to employment opportunities in static urban locations (e.g., office building, retail shop). This information is currently lacking, and limits the potential for the impact of local employment on health and wellbeing to be captured. Such tools can inform future employment planning decisions that integrate policies across multiple sectors: health, transport, economic, and social policy. The implications of this work are discussed in the following subsections and are supported with international data.

\subsection{Potential applications of the conceptual framework and spatial measures}

The identification of employment-related neighbourhood spatial measures is important for three reasons. First, policy makers and planners can apply these measures to understand how different urban regions or areas support or hinder access to employment opportunities. This is important from an equity perspective. Second, the conceptual framework can be applied to examine the likely impact of different urban, economic, transport and social policies on access to employment opportunities, which can help identify and mitigate any unintended consequences prior to implementation. Last, and perhaps most importantly, these spatial measures can be used to monitor urban and social planning policies over time to understand their health and wellbeing impact on the location of the labour force, job seekers, and residents. For these reasons, the utilisation of spatial measures is 
beginning to generate considerable interest in the built environment and health literature and in policy (State Government Victoria 2014). Not only are the proposed spatial measures generally straightforward to calculate and apply, their objectivity and capacity to compare various urban settings simultaneously is important for identifying where inequities lie and opportunities for intervention (H Badland et al. 2014b).

The intention is to apply the majority of these measures at the SA1 level, and therefore detect localised areas of advantage or disadvantage that may exist within a neighbourhood. Such information can be used to inform interventions seeking to improve access to employment or monitor localised urban employment levels. However, it is unlikely that the majority of people across cities live and work within the same neighbourhood (Department of State Development 2013). For this reason the skill match of residents to 'local' workforce opportunities will be operationalised at the SA3 level within the Australian context. However, we acknowledge the SA3 is an administrative boundary that likely has little impact on travelling patterns (Lyseen et al. 2014); it may be that those who live closer to a SA3 perimeter have greater potential to access employment opportunities located in a contiguous SA3.

\subsection{Distribution of the labour market}

Importantly the majority of the measures we identified were based on physical access to employment, such as commute mode and distance. These measures are in part proxies for the distribution of the labour market. Researchers (Kjellstrom and Hinde 2006; Zhao et al. 2011) have argued for a more decentralised labour force across a given region, whereby jobs are dispersed across the region, rather than centrally located. This is also reflected locally in Victorian urban planning policies, whereby a series of 'activity centres' are planned to be strategically distributed throughout the region to provide greater opportunities for local employment, services, and socialisation (State Government Victoria 2014). Generally creating agglomerated activity centres serves to: reduce traffic congestion as vehicles are more evenly distributed across the road network (Cervero and Duncan 2006); increase the number and diversity of local employment opportunities available (Kjellstrom and Hinde 2006); and make active travel and public transport viable and appealing options, due to reduced commute distances, more local destinations available, and increased availability of public transport infrastructure (H Badland et al. 2014a). Indeed, one of our recent studies demonstrated that, compared with those who had no access to public transport infrastructure, those who had public transport infrastructure located close to both their residence and primary workplace, were 16 times more likely to commute to work by bus or train (H Badland et al. 2014a).

\subsection{Limitations}

This work has some limitations. First, our upstream measures focussed only on the location of a single employment location (deemed to be the primary location); yet many people work in multiple locations (e.g., tradespeople) or engage in several jobs located at different sites. In Australia, 92\% of 
employees work in one job (Milner et al. under review); however we were unable to source metrics regarding the prevalence of people who work in multiple locations as part of a single job. We have been unable to source metrics that identify the prevalence of these in the Australian context. It is likely that working across multiple locations generates additional commuting time that can disproportionally impact on aspects of the conceptual framework, and indeed, these types of employment may not be appropriate to access using walking, cycling, or public transport. Second, income and education access variables were not included in the final conceptual framework. Although both are related to employment opportunities, they are confounded with both the exposure and outcome variables (Mackinnon et al. 2000). Third, we recognise this conceptual framework does not necessarily capture all the nuances of employment and the implications diverse employment has on health and wellbeing outcomes. As such, we recommend caution when applying this framework if the intention is to focus on certain employment groups (e.g., migrant workers, shift workers, those working in multiple locations) or peri-urban / rural settings, as the behavioural and intermediate outcomes may have a disproportionate impact on health and wellbeing outcomes for these people when compared with the more upstream neighbourhood determinants. Nevertheless, this framework hypothesises a series of employment measures that can initially be tested and refined over time, with the aim of enhancing and informing urban planning policies.

\subsection{Next stages}

The next stages will involve sourcing appropriate spatial data for each of these proposed measures. As noted earlier, these proposed measures were designed to use routine data sources, including, where available, national census data. The benefits of using such data mean that they are representative, are updated regularly and are available nationally, which add utility to the measures allowing comparison within and between cities. Once created, we will apply these measures at the nominated scales within metropolitan and large regional centres (in this case, Victoria Australia), and validate the spatial measures by linking them with existing population health and social survey data. Exploring these associations will allow us to further understand how planning and policy decisions impact on health and wellbeing through the employment pathway. 


\section{References}

Australian Bureau of Statistics (2011a). Australian Rural Profile. Canberra: Australian Bureau of Statistics.

Australian Bureau of Statistics (2011b). Statistical geography fact sheet. Canberra: Australian Bureau of Statistics.

Australian Bureau of Statistics (2012). New data from the 2011 Census released today: Occupation.

Badland, H., Hickey, S., Bull, F., \& Giles-Corti, B. (2014a). Public transport access and availability in the RESIDE study: Is it taking us where we want to go? Journal of Transport and Health, 1, 45-49.

Badland, H., Schofield, G., \& Schluter, P. (2007). Objectively measured commute distance: Associations with actual travel modes and perceptions to place of work or study in Auckland, New Zealand. Journal of Physical Activity \& Health, 4(1), 80-86.

Badland, H., Whitzman, C., Lowe, M., Davern, M., Aye, L., Butterworth, I., et al. (2014b). Urban liveability: Emerging lessons from Australia for exploring the potential for indicators to measure the social determinants of health. Social Science \& Medicine, 111, 64-73.

Baum, F., Ziersch, A., Zhang, G., \& Osborne, K. (2009). Do perceived neighbourhood cohesion and safety cohesion contribute to neighbourhood differences in health? Health \& Place, 15(4), 925-934.

Brownson, R., Boehmer, T., \& Luke, D. (2005). Declining rates of physical activity in the United States: What are the contributors? Annual Review of Public Health, 26, 421-443.

Cervero, R., \& Duncan, M. (2006). Which reduces vehicle travel more: Jobs-housing balance or retailhousing mixing? Journal of the American Planning Association, 72(4), 475-490.

Chaloff, J. (2008). Management of low-skilled labour migration. International Migration Outlook. Paris: OECD.

Chandola, T., Ferrie, J., Sacker, A., \& Marmot, M. (2007). Social inequities in self-reported health in early old age: Follow-up of prospective cohort study. BMJ, 334(7601), 990-994.

Currie, G., \& Delbosc, A. (2011). Mobility vs. affordability as motivations for car ownership choice in urban fringe, low income Australia. In K. Lucas, E. Blumenberg, \& R. Weinberger (Eds.), Auto motives: Understansing car use behaviours (pp. 193-208). Bingley: Emerald Publishing Group.

Department for Transport (2013). National travel survey statistics. London: Department for Transport.

Department of State Development, B. a. I. (2013). Industry atlas of Victoria 2013. Melbourne: Department of State Development, Business and Innovation.

Dobbs, L. (2005). Wedded to the car: women, employment, and the importance of private transport. Transport Policy, 12(3), 266-278.

Florida, R. (2011). The rise of the creative class: Revisited. New York: Basic Books.

Frank, L., Andresen, M., \& Schmid, T. (2004). Obesity relationships with community design, physical activity, and time spent in cars. American Journal of Preventive Medicine, 27(2), 87-96.

Galster, G. (2010). The mechanism(s) of neighborhood effects. Theory, evidence, and policy implications. Paper presented at the ESRC Seminar: Neighbourhood effects: Theory \& Evidence, St Andrews University, Scotland, 4 - 5 February

Jackson, L. (2003). The relationship of urban design to human health and condition. Landscape and Urban Planning, 64, 191-200.

Kjellstrom, T., \& Hinde, S. (2006). Car culture, transport policy, and public health. In I. Kawachi, \& S. Wamala (Eds.), Globalization and Health (pp. 98-121). New York: Oxford University Press.

Korsu, E., \& Wenglenski, S. (2010). Job accessibility, residential segregation and risk on long-term unemployment in the Paris region. Urban Studies, 47, 2279-2324.

Kwan, M.-P. (2012). The uncertain geographic context problem. Annals of the Association of American Geographers, 102(5), 958-968.

Learnihan, V., Van Neil, K., Giles-Corti, B., \& Knuiman, M. (2011). Effect of scale on the links between walking and urban design. Geographical Research, 49(2), 183-191.

Lowe, M., Whitzman, C., Badland, H., Davern, M., Hes, D., Aye, L., et al. (2013). Liveable, Health, Sustainable: What are the key indicators for Melbourne neighbourhoods? Place, Health, and Liveability Research Program (Vol. Research paper 1): University of Melbourne.

Lyseen, A., Nøhr, C., Sørensen, E., Gudes, O., Geraghty, E., Shaw, N., et al. (2014). A review and framework for categorizing current research and development in health related geographical information systems (GIS) studies. Yearbook of Medical Informatics, 9, 110-124. 
Mackinnon, D., Krull, J., \& Lockwood, C. (2000). Equivalence of the mediation, confounding and suppression effect. Preventive Science, 1, 173-181.

Milner, A., Kavanagh, A., Krnjacki, L., Bentley, R., \& LaMontagne, A. (2013). Area-level unemployment and job insecurity: Evidence from a longitudinal study conducted in the Australian working age population. Annuals of Occupational Hygiene, 1-10, doi:10.1093/annhyg/met066.

Milner, A., Page, S., \& LaMontagne, A. (2014). Cause and effect in studies of unemployment, mental health, and suicide: A meta-analytic and conceptual review. Psychological Medicine, 44, 909917.

Milner, A., Smith, P., \& LaMontagne, A. (under review). Workign hours and mental health: Evidence from an Australian population-based cohort, 2001 to 2012. Occupational and Environmental Medicine.

New South Wales Planning and Infrastructure (2014). Community guide: Draft metropolitan strategy for Sydney to 2031. Sydney: New South Wales Planning and Infrastructure.

Roberts, K. (2012). Country note: Australia. Education at a glance: OECD indicators 2012. Paris: OECD.

Roelfs, D., Shor, E., Davidson, K., \& Schwartz, J. (2011). Losing life and livelihood: A systematic review and meta-analysis of unemployment and all-cause mortality. Social Science \& Medicine, 72, 840-854.

Sanchez, T. (1999). The connection between public transit and employment. Journal of the American Planning Association, 65(3), 284-297.

State Government Victoria (2014). Plan Melbourne. Metropolitan planning strategy 2014. Melbourne: State Government Victoria.

Stoll, M. (2005). Geographical skills mismatch, job search and race. Urban Studies, 42, 695-717.

Strategic Review of Health Inequalities in England post-2010 (2010). Fair society, healthy lives. London: Department of Health.

Theorell, T. (2000). Working conditions and health. In L. Berkman, \& I. Kawachi (Eds.), Social Epidemiology (pp. 95-117). New York: Oxford University Press.

US Department of Transportation, \& Bureau of Transportation Statistics (2003). NHTS: Highlights of the 2001 National Household Travel Survey. Washington, DC: US Department Transport Bureau and Transportation Statistics.

van Lenthe, F., Borrell, L., Costa, G., Diez Roux, A., Kauppinen, T., Marinacci, C., et al. (2005). Neighbourhood unemployment and all cause mortality: A comparison of six countries. Journal of Epidemiology and Community Health, 59, 231-237.

Van Rooy, D. (2006). Effects of automobile commute characteristics on affect and job candidate evaluations. Environment and Behavior, 38(5), 626-655.

Warr, D., Feldman, P., Tacticos, T., \& Kelaher, M. (2009). Sources of stress in impoverished neighbourhoods: Insights into links between neighbourhood environments and health. Australian and New Zealand Journal of Public Health, 33(1), 25-35.

Weir, M., Weintraub, J., Humphreys, E., Seto, E., \& Bhatia, R. (2009). An area-level model of vehiclepedestrian injury collisions with implications for land use and transportation planning. Accident Analysis and Prevention, 41(1), 137-145.

Western Australian Planning Commission, \& Department for Planning and Infrastructure (2009). Liveable neighbourhoods: A Western Australian Government sustainable cities initiative. (2 ed.). Perth: Western Australian Planning Commission.

Wilkinson, R., \& Marmot, M. (2003). Social determinants of health: The solid facts. Copenhagen: World Health Organization.

Wilson, J. (2000). Volunteering. Annual Review of Sociology, 26(215-240).

Wilson, K., Stemp, K., \& McGinty, S. (2011). Re-engaging young people with education and training. What are the alternatives. Youth Studies Australia, 30, 32-39.

Zhao, P., Lu, B., \& de Roo, G. (2011). The impact of urban growth on commuting patterns in a restructuring city: Evidence from Beijing. Papers in Regional Science, 90, 735-754.

Figure 1. Conceptual framework of employment and health and wellbeing, specifying neighbourhood attributes, behaviours and intermediate and long-term outcomes 


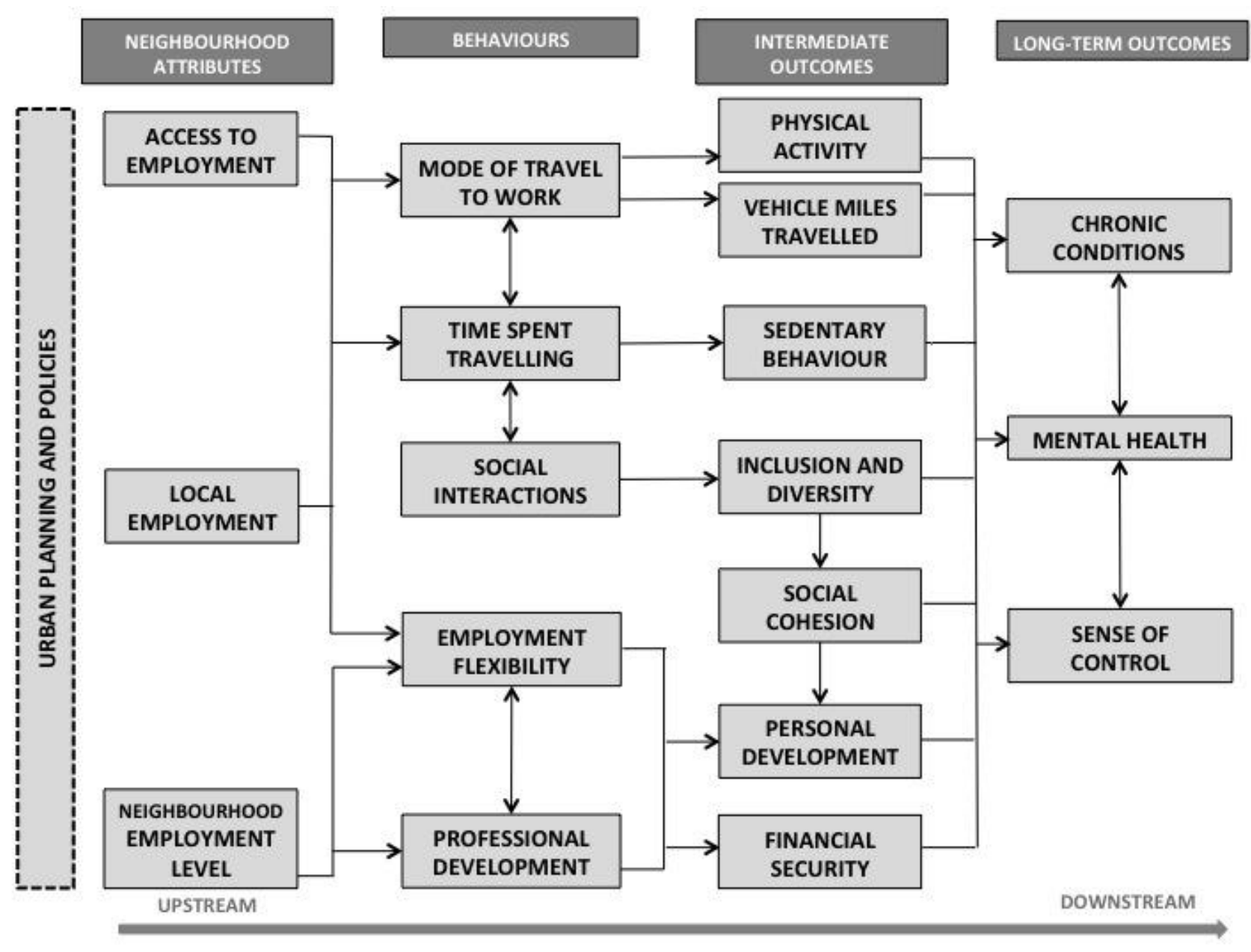


Figure 2. Percentage of the total population who live and work in the same SA3 within metropolitan Melbourne (colour version for online publication)

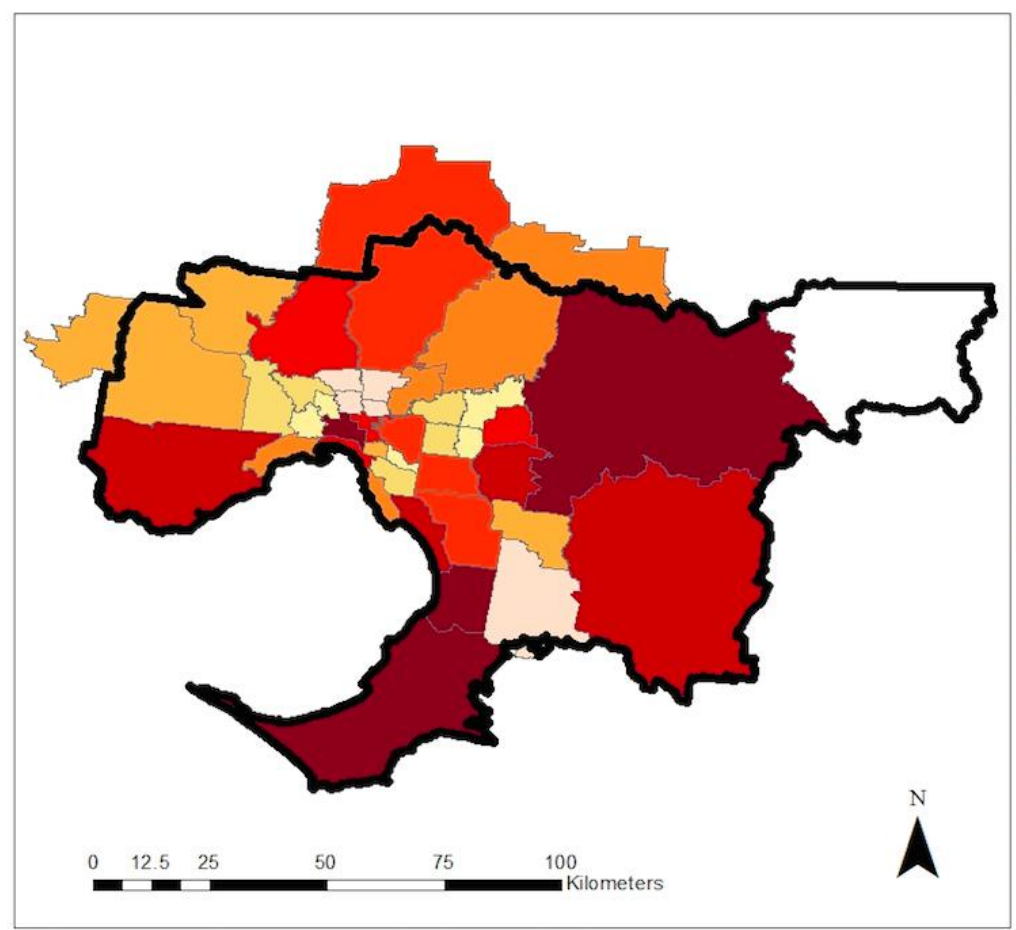

Percentage of the

Total Population who

Live and Work

in the Same SA3

Metropolitan Melbourne Zone

\section{口}

Percentage

$\square 07-765$

$7.66-8.45$

$8.46-9.64$

$9.65-11.13$

$\square 11.14-11.85$

$11.86-12.50$

$12.51-13.69$

$13.70-14.70$

$14.71-29.49$

Figure 2. Percentage of the total population who live and work in the same SA3 within metropolitan Melbourne (grey-scale version for print publication)

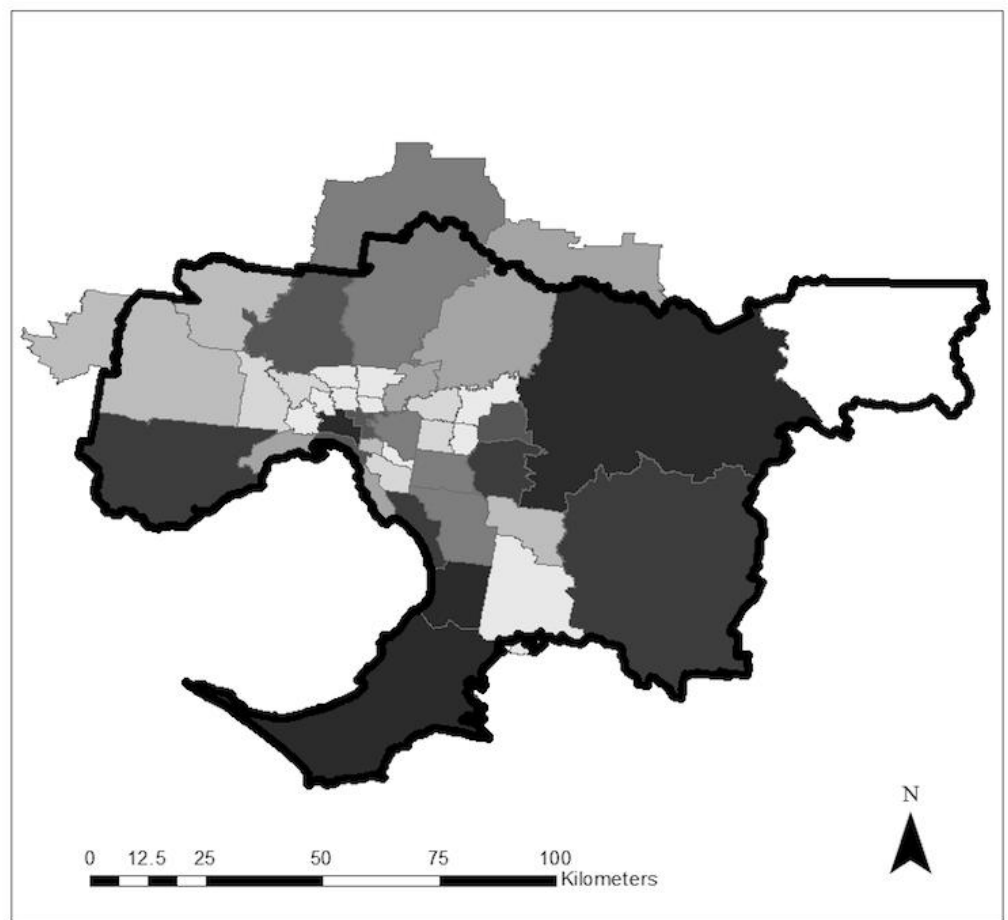

Percentage of the

Total Population who

Live and Work

in the Same SA3

Metropolitan Melbourne Zone

Percentage

$\square 5.07-7.65$

$7.66-8.45$

\ $8.46-9.64$

$9.65-11.13$

$\square 11.14-11.85$

$1186-1250$

$12.51-13.69$

$13.70-14.70$

$14.71-29.49$

Table 1. Proposed selection of spatially attributable employment measures, supporting references, regional data sources required, and intended scale for operation 


\begin{tabular}{|c|c|c|c|}
\hline \multicolumn{4}{|l|}{ ACCESS TO EMPLOYMENT } \\
\hline Measure & References & Data sources & Scale \\
\hline $\begin{array}{l}\text { Percentage of working adults } \\
\text { domiciled in an SA1 that access main } \\
\text { place of employment by public } \\
\text { transport as the primary mode (e.g., } \\
\text { train, bus, ferry, tram) }\end{array}$ & $\begin{array}{l}\text { Australian Bureau } \\
\text { of Statistics (2011) }\end{array}$ & $\begin{array}{l}\text { Road network: PSMA } \\
\text { Administrative boundaries: } \\
\text { ABS } \\
\text { Zoning: VicMap } 2012 \\
\text { Workplace commute travel } \\
\text { mode: ABS }\end{array}$ & SA1 \\
\hline $\begin{array}{l}\text { Percentage of working adults } \\
\text { domiciled in an SA1 that access main } \\
\text { place of employment by active travel } \\
\text { as the primary mode (e.g., walking, } \\
\text { cycling) }\end{array}$ & $\begin{array}{l}\text { Australian Bureau } \\
\text { of Statistics (2011) }\end{array}$ & $\begin{array}{l}\text { Road network: PSMA } \\
\text { Administrative boundaries: } \\
\text { ABS } \\
\text { Zoning: VicMap } 2012 \\
\text { Workplace commute travel } \\
\text { mode: ABS }\end{array}$ & SA1 \\
\hline $\begin{array}{l}\text { Percentage of working adults } \\
\text { domiciled in an SA1 that access main } \\
\text { place of employment by private motor } \\
\text { vehicle as the primary mode (e.g., car } \\
\text { driver or passenger, taxi, truck, van, } \\
\text { motorbike, scooter) }\end{array}$ & $\begin{array}{l}\text { Australian Bureau } \\
\text { of Statistics (2011) }\end{array}$ & $\begin{array}{l}\text { Road network: PSMA } \\
\text { Administrative boundaries: } \\
\text { ABS } \\
\text { Zoning: VicMap } 2012 \\
\text { Workplace commute travel } \\
\text { mode: ABS }\end{array}$ & SA1 \\
\hline $\begin{array}{l}\text { Mean road network distance }(\mathrm{km}) \\
\text { from populated-weighted centroid of } \\
\text { SA1 to main place of employment }\end{array}$ & $\begin{array}{l}\text { No source } \\
\text { identified }\end{array}$ & $\begin{array}{l}\text { Road network: PSMA } \\
\text { Administrative boundaries: } \\
\text { ABS } \\
\text { Zoning data: VicMap } 2012 \\
\text { Public transport stops and } \\
\text { stations: VicPT stops } 2012\end{array}$ & SA1 \\
\hline \multicolumn{4}{|l|}{ LOCAL EMPLOYMENT } \\
\hline Measure & References & Data sources & Scale \\
\hline $\begin{array}{l}\text { Percentage of employed people living } \\
\text { and working within the same SA3 }\end{array}$ & $\begin{array}{l}\text { Department of } \\
\text { State } \\
\text { Development, } \\
\text { Business and } \\
\text { Innovation (2013) } \\
\end{array}$ & $\begin{array}{l}\text { Administrative boundaries: } \\
\text { ABS } \\
\text { Zoning: VicMap } 2012 \\
\text { Employment status: ABS } \\
\text { Employment location: ABS }\end{array}$ & SA3 \\
\hline \multicolumn{4}{|l|}{$\begin{array}{l}\text { NEIGHBOURHOOD EMPLOYMENT } \\
\text { LEVEL }\end{array}$} \\
\hline Measure & References & Data sources & Scale \\
\hline $\begin{array}{l}\text { Percentage of working age adults } \\
\text { employed per SA1 }\end{array}$ & $\begin{array}{l}\text { Department of } \\
\text { State } \\
\text { Development, } \\
\text { Business and } \\
\text { Innovation (2013) }\end{array}$ & $\begin{array}{l}\text { Administrative boundaries: } \\
\text { ABS } \\
\text { Zoning: VicMap } 2012 \\
\text { Employment status: ABS } \\
\text { Employment location: ABS }\end{array}$ & SA1 \\
\hline
\end{tabular}

Key: ABS = Australian Bureau of Statistics; km = kilometre; PSMA = Public Sector Mapping Agency; SA1 = statistical area $1 ;$ SA3 = statistical area 3. 